TENNSTEDT, Florian, WINTER, Heidi, DOMEINSKI, Heinz, Quellensammlung zur Geschichte der deutschen

Sozialpolitik, 1867-1914: Von der

Haftpflichtgesetzgebung zur ersten

Unfallversicherungsvorlage

\title{
Sandrine Kott
}

\section{OpenEdition}

\section{Journals}

Édition électronique

URL : http://journals.openedition.org/ifha/1575

DOI : 10.4000/ifha. 1575

ISSN : 2198-8943

Éditeur

IFRA - Institut franco-allemand (sciences historiques et sociales)

Référence électronique

Sandrine Kott, «TENNSTEDT, Florian, WINTER, Heidi, DOMEINSKI, Heinz, Quellensammlung zur Geschichte der deutschen Sozialpolitik, 1867-1914: Von der Haftpflichtgesetzgebung zur ersten Unfallversicherungsvorlage », Revue de l'IFHA [En ligne], Date de recension, mis en ligne le 01 janvier 1996, consulté le 22 septembre 2020. URL : http://journals.openedition.org/ifha/1575 ; DOI : https:// doi.org/10.4000/ifha. 1575

Ce document a été généré automatiquement le 22 septembre 2020.

(C)IFHA 


\title{
TENNSTEDT, Florian, WINTER, Heidi, DOMEINSKI, Heinz,
} Quellensammlung zur Geschichte der deutschen Sozialpolitik, 1867-1914: Von der Haftpflichtgesetzgebung zur ersten Unfallversicherungsvorlage

\section{Sandrine Kott}

\begin{abstract}
Avec ce volume, F.T. et H.W. poursuivent l'œuvre d'édition des sources sur la politique sociale allemande entre 1867 et 1914 . Cette entreprise constitue un élément du grand projet d'édition des sources de l'histoire allemande au XIXe s. initié dès 1917 par la commission historique de l'académie des sciences et littérature de Prusse. En 1919, Friedrich Meinecke, alors directeur de la commission, avait chargé un de ses élèves, Hans Rothfels, des volumes concernant la politique sociale. Bien qu'ayant beaucoup travaillé sur la période bismarckienne, Rothfels ne put toutefois jamais venir à bout du travail d'édition (sur les raisons de cette "difficulté«, cf. Lothar MACHTAN, "Hans Rothfels und die sozialpolitische Geschichtsschreibung in der Weimarer Republik«, in: DU MÊME (dir.), Bismarcks Sozialstaat. Beiträge zur Geschichte der Sozialpolitik und zur sozialpolitischen Geschichteschreibung, Frankfurt: Campus, 1994, p.310-384; sur ses conséquences, cf. Kristian KÄHLER, »Zur Entwicklung der Geschichtsschreibung in den 1950er Jahren «, ibidem, p.451-472). Après la Seconde guerre mondiale, Peter Rassow reprit la direction de l'entreprise et le premier volume de sources sur la politique sociale entre 1867 et 1914 parut en 1967. Comme ce fut le cas pour les suivants il évitait toutefois la période bismarckienne (l'ouvrage introductif édité par K.-E. BORN est paru en 1966 à Wiesbaden. Deux volumes ont ensuite été édités par H.-J. HENNING et K.-E. BORN, rassemblant les sources pour 1905, (Wiesbaden, 1982) et 1906 (Stuttgart, 1987)). Pendant longtemps, seul le livre de Walter Vogel, archiviste à Potsdam (Bismarcks Arbeiterversicherung, Braunschweig, 1951), permit donc d'avoir une vue synthétique
\end{abstract}


sur la phase de constitution de la politique sociale allemande. Ainsi resitué dans l'histoire différée de sa publication ce volume acquiert toute sa signification et son importance.

F.T., le meilleur connaisseur actuel de la politique sociale allemande du XIXe s., a choisi, à la différence de ce qui avait été fait dans les volumes précédents, de présenter les sources de manière thématique. Le volume s'attache donc à l'émergence de la seule assurance accidents, de la loi de 1871 de responsabilité civile jusqu'au dépôt du premier projet en 1881. Les discussions autour des deux autres projets feront l'objet de prochains volumes. Les documents proviennent en grande majorité des archives du gouvernement du Reich ou celui de Prusse, mais certains émanent également du fonds de l'entreprise Krupp. En permettant de suivre l'émergence de la première loi d'assurance du Reich ils livrent une signification de l'État social allemand. Leur nature, mais également le découpage chronologique choisi (1878, début des lois antisocialistes n'est plus retenu comme une rupture) incite à minorer la fonction politique et répressive (lutte contre la social-démocratie) des mesures sociales bismarckienne. En revanche les lettres et mémoires émanant d'industriels ou de compagnies d'assurance invitent à réévaluer leur portée économique. Mais surtout, en plaçant le projet de 1881 en regard de la loi de 1871 on est conduit à voir, comme l'avait déjà fait François Ewald pour la France (L'État Providence, Paris, 1986), les débats autour de l'assurance accidents comme un témoignage $\mathrm{du}$ changement de paradigme introduit par l'industrie. A la responsabilité individuelle, à la notion de faute, l'industrialisation contraint de substituer celle de risque inévitable. L'assurance constituerait une réponse à ce changement à en faire un instrument de renforcement de l'État.

L'ouvrage, instrument de travail essentiel pour les spécialistes de la politique sociale allemande, est également d'un très grand intérêt pour tout historien de l'histoire du Kaiserreich. Dans les conflits et tensions qui s'expriment lors de l'élaboration de ce premier projet d'assurance accidents on peut en effet distinguer ce qui oppose les différents départements d'État, ils permettent d'apprécier le rôle de Bismarck et plus largement le fonctionnement $\mathrm{du}$ gouvernement du Reich et la manière dont les décisions politiques sont prises durant la première phase du Kaiserreich. Ils illustrent enfin la nature des relations entre pouvoirs politiques et économiques durant la même période.

Sandrine KOTT 